\title{
Stimuli-responsive chitosan-starch injectable hydrogels combined with encapsulated adipose-derived stromal cells for articular cartilage regeneration $\dagger$
}

\author{
Helena Sá-Lima, ${ }^{* a b}$ Sofia G. Caridade, ${ }^{a b}$ João F. Mano ${ }^{a b}$ and Rui L. Reis ${ }^{a b}$ \\ Received 1st March 2010, Accepted 20th May 2010 \\ DOI: 10.1039/c0sm00041h
}

Tissue engineering strategies have been showing promising early results in articular cartilage lesions repair. Hydrogels based on natural origin polymers as chitosan glycerol-phosphate (CGP) thermosensitive formulation that can be implanted in a minimal invasive manner, represent a great promise as injectable scaffold choice for cartilage tissue engineering, but it lacks in mechanical properties.

A different formulation, from which a firm texture gels results is, therefore, desirable.

In this work we first aim to investigate the suitability of CGP to produce an injectable thermosensitive, $\mathrm{pH}$-dependent solution, when combined with increasing concentrations of starch: $0.5 \%$ (I), $1 \%$ (II), and $1.5 \%$ (III). The data collected from the rheological measurements showed that the addition of starch to the CGP did not alter the transition temperature and confirmed the heating inducing gelation of all solutions, supporting the ability of these novel formulations to be applied as minimal invasive systems. The evaluation of the dynamic mechanical analysis of the hydrogels showed an increase in the storage modulus within increasing starch concentration, clearly demonstrating that best viscoelastic properties were obtained with the novel chitosan-starch based solution. The incorporation of starch also improved the degradation profile. All materials showed to be biocompatible through the cytotoxicity screening in vitro. These data suggested the potential of novel thermo-responsive chitosan-starch hydrogels to be used as injectable vehicles for cell delivery in cartilage tissue engineering applications.

In a second phase, the potential of chitosan- $\beta$-glycerophosphate (CGP) and chitosan- $\beta$ glycerophosphate- $1 \%$ starch (CST) hydrogels to induce chondrocytic differentiation and cartilage matrix accumulation were evaluated, as well as the influence of starch in the chondrogenesis of encapsulated adipose derived stromal (ADSC) cells. The ADSC were homogeneously encapsulated, remained viable, proliferated, and maintained the expression of typical chondrogenic markers genes, and deposited cartilage ECM molecules. Improved results were obtained within the novel CST constructs. The overall data suggest that chitosan- $\beta$-glycerophosphate-starch hydrogels could be considered for chondrogenic differentiation of adipose derived stromal cells for cartilage-engineered regeneration using minimal invasive techniques.

\section{Introduction}

Articular cartilage defects resulting from injury or osteochondral diseases may lead to degenerative arthritis and affect the daily living activities. The incidence of cartilage pathologies is increasing each year, and consequently, more clinical procedures to repair the damaged tissue are being executed. Recent advances in therapeutic strategies have been showing encouraging results and are now beginning to shape clinical practice. The regeneration of cartilaginous tissue of better quality is due to the continuous improvements in tissue engineering and cell-based

a3B's Research Group - Biomaterials, Biodegradables and Biomimetics, University of Minho, Headquarters of the European Institute of Excellence on Tissue Engineering and Regenerative Medicine, AvePark, Zona Industrial da Gandra S. Cláudio de Barco, 4806-909 Caldas das Taipas, Guimarães, Portugal.E-mail: hlima@dep.uminho.pt

${ }^{b} I B B$ - Institute for Biotechnology and Bioengineering, PT Government Associated Laboratory, Guimaräes, Portugal

$\dagger$ This paper is part of a joint Soft Matter and Journal of Materials Chemistry themed issue on Tissue Engineering. Guest editors: Molly Stevens and Ali Khademhosseini. therapies and their different elements, by combining chondrogenic cells, biomaterial scaffolds, and suitable culture conditions. ${ }^{1-3}$

The selection of an appropriate scaffold is of extremely importance, since it will act as a temporary three-dimensional (3D) support for cell growth, differentiation and production of extracellular matrix (ECM), providing the environment for the chondrocytic phenotype maintenance or restoring, and thus playing an important role in the new tissue formation. ${ }^{4,5}$ There are a number of biomaterial options as a cell-carrying scaffold for cartilage tissue engineering applications, which can be natural, synthetic, or a combination of both. Many of these are smart hydrogels that could potentially be injected throughout a minimal invasive transplantation. ${ }^{6-10}$ Additionally these water swellable networks exhibit higher water contents, and macromolecular structure similar to native tissue, making them an ideal vehicle to transfer cells to articular defects. ${ }^{11,12}$

Chitosan (C) is an aminopolysaccharide derived from partial depolymerisation and deacetylation of chitin found in the shells of crustaceans, and has been widely suggested for many different 
hydrogel matrices in cartilage applications (Fig. 1A). ${ }^{13,14}$ In 2000, Chenite and colleagues developed a new approach based on the neutralization of chitosan by adding polyol-phosphate salts, such as $\beta$-glycerophosphate (GP), to produce an injectable thermosensitive, $\mathrm{pH}$-dependent solution, which is liquid at physiological $\mathrm{pH}$ and room temperature, and becomes a gel if heated at body temperature. ${ }^{15-17}$ One of the drawbacks of using the chitosanglycerophosphate (CGP) system is the limited mechanical properties of hydrogels. An alternative formulation that generates a more rigid texture gel would be advantageous. ${ }^{18-20}$ Starch is a natural biodegradable material composed by two polymeric carbohydrates, amylose and amylopectin (Fig. 1B). Cartilage regeneration approaches have been implemented using starchbased polymers due to their good biodegradable, biocompatible, and processing versatility properties. ${ }^{21-24}$

In this work we first aim to investigate the suitability of CGP as a cell delivery vehicle when combined with increasing concentrations of starch: $0.5 \%$ (I), 1\% (II), and 1.5\% (III). The mechanical behaviour of these new CGP-starch based (CS) systems was characterized trough dynamical mechanical analysis, and rheological studies in function of temperature were also conducted. The internal morphology of the hydrogels was assessed by low temperature scanning electron microscopy cryoSEM. Degradation behaviour and cytotoxicity evaluations were also performed. In a second phase we intended to evaluate the in vitro chondrogenic differentiation of adult adipose-derived stromal cells (ADSCs) when encapsulated in CS hydrogel and compare with the system without the introduction of starch.

Owing to some limitation in using autologous chondrocytes, namely in isolating through invasive biopsies, and the dedifferentiation trend which limits the chondrogenesis capacity; ${ }^{25,26}$ many recent studies have been showing the potential and feasibility of ADSCs as cell source for cartilage tissue engineering applications. ${ }^{27-29}$ The ADSCs are multipotent cells with the ability to express distinct phenotypes under defined appropriate culture conditions, including the induction toward a chondrogenic phenotype. ${ }^{30}$ The multipotency attribute, together with the self-renewal, and division ability are along with the appealing characteristics of these cells. Moreover, the adipose tissue is routinely wide available and can be harvested easily from liposuction, yielding an abundant cell number after expansion without loss of multipotentcy. ${ }^{31}$

In this study, we aimed to evaluate if the ADSCs could differentiate into chondrocyte-like cells within a CS hydrogel and maintain the chondrogenic phenotype in vitro. The chondrogenesis was assessed by molecular, biochemical, and histological techniques.

\section{Experimental (materials and methods)}

Preparation of chitosan-glycerolphosphate (CGP) and chitosanglycerolphosphate-starch (CS) hydrogels

A sterile chitosan-GP solution of $2 \%$ chitosan- $135 \mathrm{mM}$ disodium $\beta$-GP was prepared by dissolving $200 \mathrm{mg}$ of purified low molecular weight chitosan (Sigma, DD of $80 \%$ measured by NMR spectroscopy) in $6 \mathrm{~mL}$ filter-sterilized $70 \mathrm{mM} \mathrm{HCl}$. This solution was subjected to a $20 \mathrm{~min}$ autoclave sterilization, cooled to $4{ }^{\circ} \mathrm{C}$, and $1 \mathrm{~mL}$ filter-sterile $1.35 \mathrm{M} \mathrm{GP}$ (Sigma) was then added. Separately, $50 \mathrm{mg}$ (CS-I), $100 \mathrm{mg}$ (CS-II), and $150 \mathrm{mg}$ (CS-III) of potato starch (Sigma, S2630) were dispersed in $3 \mathrm{~mL}$ of water to obtain final starch concentrations of $0.5 \%, 1 \%$, and $1.5 \%(\mathrm{w} / \mathrm{v} \%)$, respectively. The solutions were autoclave sterilized and mixed with the chitosan-glycerophosphate at $4{ }^{\circ} \mathrm{C}$. The CGP system was obtained by adding $3 \mathrm{~mL}$ of autoclaved water. All the solutions were allowed to solidify for $20 \mathrm{~min}$ in a humidified, 5\% $\mathrm{CO}_{2}$ cell culture incubator at $37^{\circ} \mathrm{C}$.

\section{Rheological characterisation of thermogelling solutions}

Rheological measurements of the 4 different hydrogel conditions were conducted on a Stress-Tech HR controlled tension rheometer (Reologica Instruments $\mathrm{AB}$, Sweden), with parallel plates $(\Phi 40 \mathrm{~mm})$, requiring about $3 \mathrm{~mL}$ of solution as the sample volume. The values of the strain amplitude were chosen in order to ensure that all measurements were performed within the linear viscoelastic region. The storage modulus $\left(\mathrm{G}^{\prime}\right)$ and loss modulus $\left(\mathrm{G}^{\prime \prime}\right)$ were measured as functions of temperature, under oscillation measurements of $1 \mathrm{~Hz}\left(1 \mathrm{rad} \mathrm{s}^{-1}\right)$ and constant stress of $10 \mathrm{~Pa}$. The gap between the plates was $1 \mathrm{~mm}$. The temperature was varied, at a rate of $1{ }^{\circ} \mathrm{C} \mathrm{min}-1$, from 20 to $50{ }^{\circ} \mathrm{C}$. The gelation
A

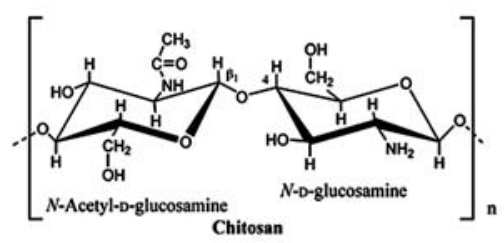

B

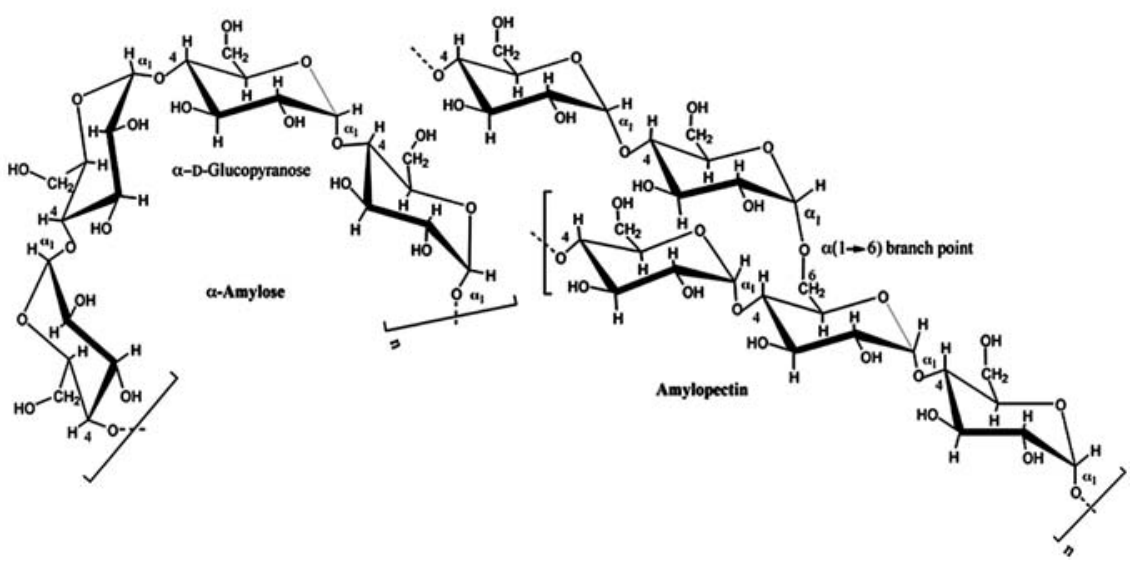

Fig. 1 Chemical structure of (A) chitosan, and (B) starch. 
point is considered as the temperature at which both $\mathrm{G}^{\prime}$ and $\mathrm{G}^{\prime \prime}$ crossover $(\tan \delta=1)$.

\section{Low temperature scanning electron microscopy - CryoSEM}

Cryogenic scanning electron microscopy was used to evaluate the inner microstructure of the hydrogels. CryoSEM was conducted on CEMUP SE equipment. The samples were placed in a chamber, fractured and sublimated for $10 \mathrm{~min}$ at $-95^{\circ} \mathrm{C}$.

\section{Fourier-transform infrared spectroscopy - FT-IR}

The chemical composition of potato starch (Sigma, S2630) was evaluated by fourier-transform infrared spectroscopy (FTIR) using FTIR-IR Prestige-21 (Shimadzu). Prior analysis, transparent sample/KBr discs (ratio $1: 10$ ) were prepared by uniaxially pressing. Transmission spectra were recorded in the spectral range of $4000-500 \mathrm{~cm}^{-1}$ using at least 32 scans with $4 \mathrm{~cm}^{-1}$ resolution.

\section{Dynamic mechanical analysis - DMA}

The viscoelastic measurements were performed using a TRITEC8000B DMA from Triton Technology (UK), equipped with the compressive mode. All hydrogel conditions were prepared as described previously and were cut in cylindrical shapes with about $6 \mathrm{~mm}$ diameter and $4 \mathrm{~mm}$ thickness. The geometry of the samples was then measured and the samples were clamped in the DMA apparatus and immersed in the PBS solution. Hydrogels were always analyzed immersed in a liquid bath of PBS placed in a Teflon ${ }^{\circledR}$ reservoir and the measurements were carried out at $37^{\circ} \mathrm{C}$ of temperature. After equilibration, the DMA spectra were obtained during a frequency scan between 0.1 and $10 \mathrm{~Hz}$. The experiments were performed under constant strain amplitude $(50 \mu \mathrm{m})$. A small preload was applied to each sample to ensure that the entire hydrogel surface was in contact with the compression plates before testing. Three samples were used for each condition.

\section{In vitro enzymatic degradation study}

The hydrogels were incubated in phosphate buffered saline (PBS) solution ( $\mathrm{pH} 7.4$ ) containing $\alpha$-amylase (150 $\mathrm{U} \mathrm{L}^{-1}$ and lysozyme (13 $\mathrm{mg} \mathrm{L}^{-1}$ ) at concentrations similar to the ones found in human serum, ${ }^{32,33}$ at $37{ }^{\circ} \mathrm{C}$ up to 60 days, in order to carry out the degradation studies. At different time points, the samples were removed and weighed. The weight loss $(\% \mathrm{~W})$ was calculated according to the following equation: $\% W=\frac{m_{f}-m_{i}}{m_{i}} \times 100$, where the $m_{i}$ and $m_{f}$ are the weight of the samples before and after immersion in the enzymatic degradation solutions.

\section{In vitro cytotoxicity screening on materials' extracts}

MTS (3-(4,5-dimethylthiazol-2-yl)-5-(3-carboxymethoxyphenyl)2-(4-sulfophenyl)-2 $H$-tetrazolium) test was performed to determine the cytotoxicity of chitosan-starch hydrogels leachables that might result from the gelation methodology accordingly to ISO/EN 10993-5. The CGP, CS-I, CS-II, and CS-III hydrogels were prepared as described above, and allowed to become a hard gel at $37^{\circ} \mathrm{C}$. Then they were incubated in Dulbecco's Modified
Eagle's Medium without phenol red (DMEM, Sigma) for $24 \mathrm{~h}$ at constant temperature $\left(37^{\circ} \mathrm{C}\right)$ and agitation $(60 \mathrm{rpm})$ in order to obtain the extract of the different materials containing potential toxic leachables and degradation products. The ratio of materials weight to extract fluid was constant, and equal to $0.2 \mathrm{~g} \mathrm{~mL}^{-1}$. Mouse fibroblastic-like cells (L929 cells; ECACC, UK), were cultured in the same medium and were seeded in 96-well cell culture plates $\left(10000\right.$ cells cm $\left.\mathrm{cm}^{-2}\right)$, in order to reach $80 \%$ confluence in $24 \mathrm{~h}$. The extracts were then filtered and placed in contact with the monolayer of L929 cells for 24 h, 4 days, and 7 days. At each time the viable cells, those with functional mitochondrial dehydrogenase, able to reduce the yellow substrate into a brown formazan product were determined by the MTS assay (CellTiter 96 One solution Cell Proliferation Assay kit; Promega, Madison, WI). The optical density (OD) was read at $490 \mathrm{~nm}$ with a plate reader (Synergy HTi, Bio-tek) and compared with the positive control-latex extracts, and negative control - tissue culture polystyrene (TCPS), for cell death.

\section{Chondrogenesis of human adult adipose derived stromal cells (ADSC) encapsulated in CST hydrogel}

ADSC isolation, expansion and encapsulation. Human adipose stromal derived adult cells (ADSCs) were isolated from subcutaneous lipoaspirated adipose tissue, donated from consenting patients at the Prelada Hospital - Porto, as previously described. ${ }^{34}$ Briefly, liposuction waste tissue was digested with $0.15 \%$ collagenase type II (Sigma) for about $1 \mathrm{~h}$ at $37{ }^{\circ} \mathrm{C}$ under continuous shaking. The floating adipocytes were separated from the precipitating stromal fraction by centrifugation. The stromal cells were then plated in tissue culture flasks in basic DMEM-F12 medium (Invitrogen) with 10\% foetal bovine serum (FBS, Gibco), and antibiotic-antimycotic ( $1 \% \mathrm{~A} / \mathrm{B}$, Gibco) solution containing 10000 units $\mathrm{mL}^{-1}$ penicillin $\mathrm{G}$ sodium, $10000 \mu \mathrm{g} \mathrm{mL}^{-1}$ streptomycin sulfate and $25 \mu \mathrm{g} \mathrm{mL}^{-1}$ amphotericin $\mathrm{B}$ as Fungizone ${ }^{\circledR}$ in $0.85 \%$ saline, at $37^{\circ} \mathrm{C}$ in an atmosphere containing $5 \%$ of $\mathrm{CO}_{2}$ until achieving confluence. Cells were cultured until passages 1 and 2 , at a confluence of more than $80 \%$, after which they were harvested with trypsin/EDTA, counted, and then mixed gently at room temperature in the hydrogels solutions at a concentration of 10 million cells $\mathrm{mL}^{-1}$. The chitosan- $\beta$-glycerophosphate (CGP) and chitosan- $\beta$-glycerophosphate- $1 \%$ starch (CST) solutions were prepared as described above, and the cell suspension, within the different formulations, were then dispensed into $6 \mathrm{~mm}$ diameter moulds containing $200 \mu \mathrm{L}$ of hydrogel solution per insert, allowed to gel at $37^{\circ} \mathrm{C}$ for $20 \mathrm{~min}$, then cultured in chondrogenic medium composed of DMEM-F12 basic medium containing $1 \mathrm{nM}$ dexametasone (Sigma), 0.1 M sodium pyruvate, $37.5 \mu \mathrm{g} \mathrm{mL}^{-1}$ of ascorbate-2-phosphate (SIGMA), $35 \mathrm{mM}$ proline, and $1 \times$ insulintransferrin-selenium (ITS+, Sigma), supplemented with $10 \mathrm{ng} \mathrm{mL}{ }^{-1}$ of transforming growth factor- $\beta 1$ (PrepoTech, UK), and $10 \mathrm{ng} \mathrm{mL}^{-1}$ of fibroblast growth factor-2 (PrepoTech, UK), in a humidified incubator at $37{ }^{\circ} \mathrm{C}$ under $5 \% \mathrm{CO}_{2}$ atmosphere for up to 28 days, with medium changed every 3 days.

\section{Biochemical composition}

The constructs were collected after 1, 14, and 28 days of culture, washed twice with a sterile PBS solution, and then stored at 
$-80{ }^{\circ} \mathrm{C}$. When defrosted, samples were digested overnight at $56^{\circ} \mathrm{C}$ with protease $\mathrm{K}$ in $50 \mathrm{mM}$ Tris with $1 \mathrm{mM}$ EDTA, $1 \mathrm{mM}$ iodoacetamide and $10 \mu \mathrm{g} \mathrm{mL} \mathrm{m}^{-1}$ pepstatin-A.

Cell proliferation was determined using a fluorimetric double strand DNA (dsDNA) quantification kit (PicoGreen, Molecular Probes). The fluorescence was measured using an emission of $490 \mathrm{~nm}$ and an absorbance wavelength of $520 \mathrm{~nm}$ in a plate reader (Synergy HTi, Bio-tek).

The sulfated glycosoaminoglycans (GAGs) content was measured spectrophotometrically using dimethylmethylene blue (DMB, Sigma) assay based on the method described previously. ${ }^{35}$ Chondroitin sulfate (Sigma) was used as standard solution, and the optical density was read at $525 \mathrm{~nm}$ in a plate reader (Synergy HTi, Bio-tek).

\section{Histological analysis}

Cell morphology and distribution within the constructs were examined by microscopy during the in vitro culture. Prior to histological studies, the constructs were fixed in $2.5 \% \mathrm{v} / \mathrm{v}$ paraformaldehyde for $24 \mathrm{~h}$ at $4{ }^{\circ} \mathrm{C}$, included in HistoGel (Thermo Scientific), processed and paraffin embedded. Five micrometres sections were cut and mounted onto positively charged slides. The sections were stained with Hematoxilyn-Eosin (H\&E) and Toluidine Blue for proteoglycans, following standard histological methods, and then examined microscopically and photographed.

\section{RNA extraction and analysis by real-time reverse transcriptionpolymerase chain reaction-real time RT-PCR (collagen type II, type I, aggrecan, and Sox 9)}

The real-time RT-PCR analyses were performed after 1 and 4 weeks of culture to quantitatively assess the up- and downregulation of genes typically associated with chondrogenesis. Total RNA was extracted using Tryzol reagent (Invitrogen). Briefly, the samples were collected and the cells were lysed, centrifuged at $13000 \mathrm{rpm}, 4^{\circ} \mathrm{C}$ for $15 \mathrm{~min}$ in the presence of chloroform (Sigma), and RNA precipitated by the addition of isopropanol (Sigma). After centrifugation $\left(13000 \mathrm{rpm}, 4{ }^{\circ} \mathrm{C}\right.$ for $15 \mathrm{~min}$ ), the RNA was washed in ethanol, dried and reconstituted in distilled water DNase, RNase free (Gibco). The amount of isolated RNA and A260/280 ratio was determined using NanoDrop ND-1000 Spectrophotometer (NanoDrop Technologies). Subsequently, the total RNA extracted was reverse transcribed into cDNA using the iScript ${ }^{\mathrm{TM}}$ cDNA Synthesis Kit (BioRad), following the manufacturer's protocol. Real-time PCR was performed in the MJ Mini ${ }^{\mathrm{TM}}$ Personal thermal Cycler (BioRad) using $1 \mu \mathrm{g}$ of each sample. The expression of the genes of interest - collagen type I, collagen type II, aggrecan, and Sox-9, was evaluated using MJ Opticon Monitor 3.1 software (BioRad), and the housekeeping gene glyceraldehyde-3-phosphate dehydrogenase (GAPDH) was used to normalize the marker gene expression. All primer sequences were generated using Primer $3^{\mathrm{TM}}$ software, and acquired from MWG (Biotech). The specific primer sets, nucleotide sequences and product size, and annealing temperatures for GAPDH and marker genes are summarized in Table 1.
Table 1 The specific primer sets, nucleotide sequences, and annealing temperatures for GAPDH and marker genes: collagen type I (Col I), collagen type II (Col II), Aggrecan, and Sox 9

\begin{tabular}{|c|c|c|}
\hline Gene name & Primer sequence & Annealing $T /{ }^{\circ} \mathrm{C}$ \\
\hline Col I & $\begin{array}{c}\mathrm{f} \quad 5^{\prime}-\text { AGC CAG CAG ATC GAG } \\
\text { AAC AT - } 3^{\prime} \\
\mathrm{r} \quad 5^{\prime}-\text { ACA CAG GTC TCA CCG } \\
\text { GTT TC }-3^{\prime}\end{array}$ & 58.4 \\
\hline Col II & $\begin{array}{c}\text { f } 5^{\prime}-\text { CGG TGA GAA GGG AGA } \\
\text { AGT TG- } 3^{\prime} \\
\mathrm{r} \quad 5^{\prime}-\text { GAC CGG TCA CTC CAG } \\
\text { TAG GA - } 3^{\prime}\end{array}$ & 60.4 \\
\hline Aggrecan & 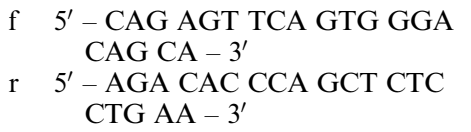 & 59.4 \\
\hline Sox 9 & $\begin{array}{c}\text { f } 5^{\prime} \text { - TTC ATG AAG ATG ACC } \\
\text { GAC GA - } 3^{\prime} \\
\mathrm{r} \quad 5^{\prime}-\text { TGC CAG TCG TAG CCC } \\
\text { TTG AG }-3^{\prime}\end{array}$ & 58.4 \\
\hline GAPDH & $\begin{array}{c}\mathrm{f} \quad 5^{\prime}-\text { ACA GTC AGC CGC ATC } \\
\text { TTC TT }-3^{\prime} \\
\mathrm{r} \quad 5^{\prime}-\text { GAC AAG CTT CCC GTT } \\
\text { CTC AG }-3^{\prime}\end{array}$ & 58.4 \\
\hline
\end{tabular}

PCR reactions were incubated for $5 \mathrm{~min}$ at $95^{\circ} \mathrm{C}$, followed by 45 cycles were used for all genes, each one consisting of: denaturation $\left(95^{\circ} \mathrm{C}, 10 \mathrm{~s}\right)$, annealing of $30 \mathrm{~s}$ (annealing temperature as shown in Table 1), and chain elongation: $\left(72^{\circ} \mathrm{C}, 30 \mathrm{~s}\right)$, followed by denaturation $\left(95^{\circ} \mathrm{C}, 1 \mathrm{~min}\right)$.

For each sample, the fluorescent cycle threshold $(\mathrm{Ct})$ values were determined automatically by the software and the relative transcript levels were calculated using $2^{-\Delta \Delta \mathrm{Ct} .}{ }^{36}$

\section{Statistical analysis}

Statistical analysis was performed using one-way analysis of variance (ANOVA) and Tukey post-hoc to determine the statistical significance as a function of culture time. A $p$ value $<0.05$ was considered statistically significant for $95 \%$ of confidence. Data are reported as mean \pm standard variation.

\section{Results and discussion}

Preparation of chitosan-glycerolphosphate (CGP) and chitosanglycerolphosphate-starch (CS) hydrogels

The minimal invasive injectable techniques using smart hydrogels as cell delivery system offers attractive features for cartilageengineered applications. ${ }^{6,10,37,38}$ The thermally sensitive, pH-dependent chitosan polyol salts solutions, first reported by Chenite et al. ${ }^{15}$ have been proposed as a treatment modality for a wide-ranging of applications that involves scaffold guided and cell delivery regenerative medicine. ${ }^{39,40}$ Our group has also been developing natural origin biomaterials for an ample range of engineered applications, such as chitosan and starch-based systems. ${ }^{22,41}$ Starch blending with biodegradable polymers, such as chitosan, may improve the materials water resistance and mechanical properties. ${ }^{42,43}$ Herein, chitosan-glycerophosphate solutions were mixed with increasing concentrations of starch solutions: $0.5 \%, 1 \%$, and $1.5 \%$, to produce CS hydrogels I, II, III, respectively. All the systems have shown to be a solution at room 
temperature, but gels are formed around physiological temperature and $\mathrm{pH}$, with similar gelation rates among all conditions. The solutions' colour changed from transparent to opaque upon heating, and no visual differences were observed in the hydrogels' appearance (data not shown).

\section{Rheological characterisation of thermogelling solutions}

It was previously reported that chitosan solutions could be neutralised up to physiological $\mathrm{pH}$ using $\beta$-GP salts, undergoing a thermal gelation upon heating. ${ }^{15,16}$

The ability of the different solutions to become a gel after heating was studied by rheological measurements. The storage modulus $\left(\mathrm{G}^{\prime}\right)$ and the loss modulus $\left(\mathrm{G}^{\prime \prime}\right)$ were measured as function of time from room temperature to $50{ }^{\circ} \mathrm{C}$. Fig. 2 shows the evolution of $\mathrm{G}^{\prime}$ and $\mathrm{G}^{\prime \prime}$ moduli of the sample CGP, CS-I, CS-II and CS-III upon heating, temperatures ranging from room temperature to $50{ }^{\circ} \mathrm{C}$.

In all cases, similar fashion curves were observed that can be described in three different regions, as it was previous demonstrated. ${ }^{44,45}$ In the first region, a common viscoelastic fluid-like behaviour of polymer solutions is detected, were increasing the temperature both storage and loss moduli decreased, being $\mathrm{G}^{\prime \prime}$ $>\mathrm{G}^{\prime}$. The second region is characterized by an abrupt increase in both $\mathrm{G}^{\prime}$ and $\mathrm{G}^{\prime \prime}$ moduli because of the sol-gel transition (establishment of hydrogel three-dimensional network). The storage modulus growth rate was also expected to be higher, indication of increasing elasticity in the system, than of the loss modulus due to the gel formation process. The gelation temperature was considered as the point at which both $\mathrm{G}^{\prime}$ and $\mathrm{G}^{\prime \prime}$ crossover $(\tan \delta=1) .{ }^{44}$ In all cases the transition temperature were found near below the body temperature, ranging from $36.3{ }^{\circ} \mathrm{C}$ in $\mathrm{CS}-\mathrm{I}$ and $36.9^{\circ} \mathrm{C}$ in CS-III hydrogels.

These results showed that the addition of starch to the chitosan-GP solution did not alter the transition temperature and confirmed the heating inducing gelation of all solutions, which remain liquid at room temperature and solidifies into white hydrogels near body temperature. The low viscosity values (Fig. 3) of these novel chitosan-starch-based hydrogels allowed us to prepare a homogeneous cell suspension at room temperature to be used as injectable delivery system through a minimal invasive procedure for cartilage regeneration.

\section{Low temperature scanning electron microscopy - cryoSEM}

The ultrastructure and morphology of the hydrogels were observed trough cryoSEM. The CGP hydrogel was previously characterized and had shown to form an open homogeneous porous network composed of chitosan where GP is unbounded and freely dispersed. Also in previous studies, SEM based techniques revealed a uniformly porous mesh-like structure, where a continuous network, with a few micrometres-thick, is surrounding the porous. ${ }^{17,46}$ The cryoSEM allows the assessment of the sub-micro structure of the gels giving images with higher
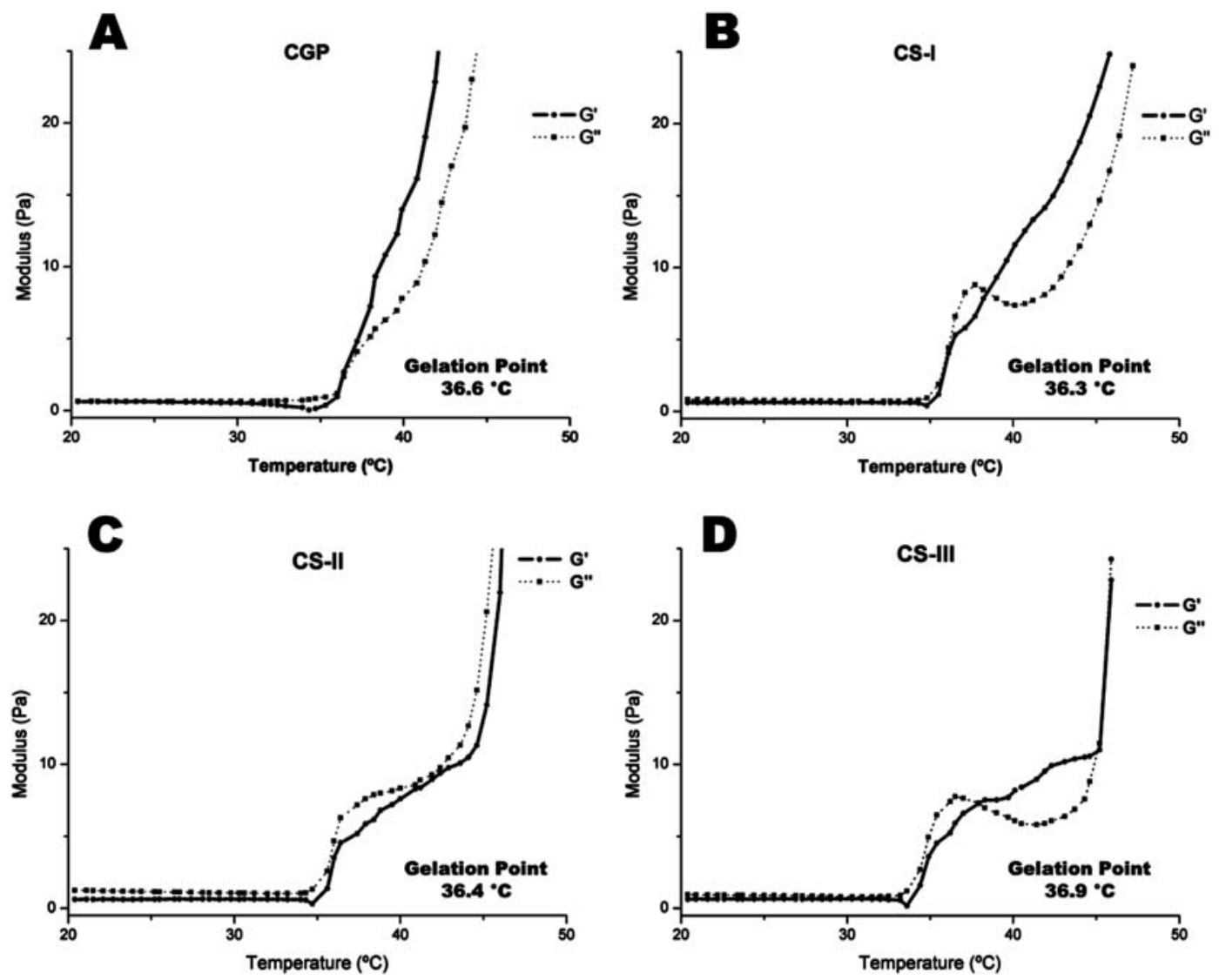

Fig. 2 Rheological results showing the evolution of storage, $\mathrm{G}^{\prime}$ and loss, G", moduli of samples: (A) CGP (B) CS-I, (C) CS-II and (D) CS-III upon heating from 20 to $50{ }^{\circ} \mathrm{C}$. 
magnification then normal SEM techniques. Fig. 4A shows a typical overall appearance of CGP hydrogel where it is possible to see an open and beaded-like network structure, constituted by linking polymeric clusters assembled in agglomerates and chains. This structure provides a uniform matrix in which cells can be encapsulates in a rather uniform way. The hydrogels containing starch led to structures with similar morphologies although the network appeared to be more open in the starch ones (Fig. 4B-D). This less dense matrix, compared with CGP condition, was found among all CS systems, and the addition of increasing concentrations of starch did not produce considerable changes in the morphology of the starch based hydrogels. Although further studies will be need to explain this particular feature in the CS scaffolds, it can be related with the hydrophilicity of starch which augments the water retention in new developed hydrogels, and thus creating this more open network structure.

\section{Dynamical mechanical analysis - DMA}

The clinical success of tissue-engineered constructs is highly related with the mechanical properties of the engineering constructs, which should match the tissue intended to be regenerated ${ }^{47,48}$ Cartilage clearly exhibits viscoelastic properties and their mechanical response is mainly related with the solid components of the extracellular matrix (ECM), such as proteoglycans and collagens, but also strongly tied to the flow of fluid
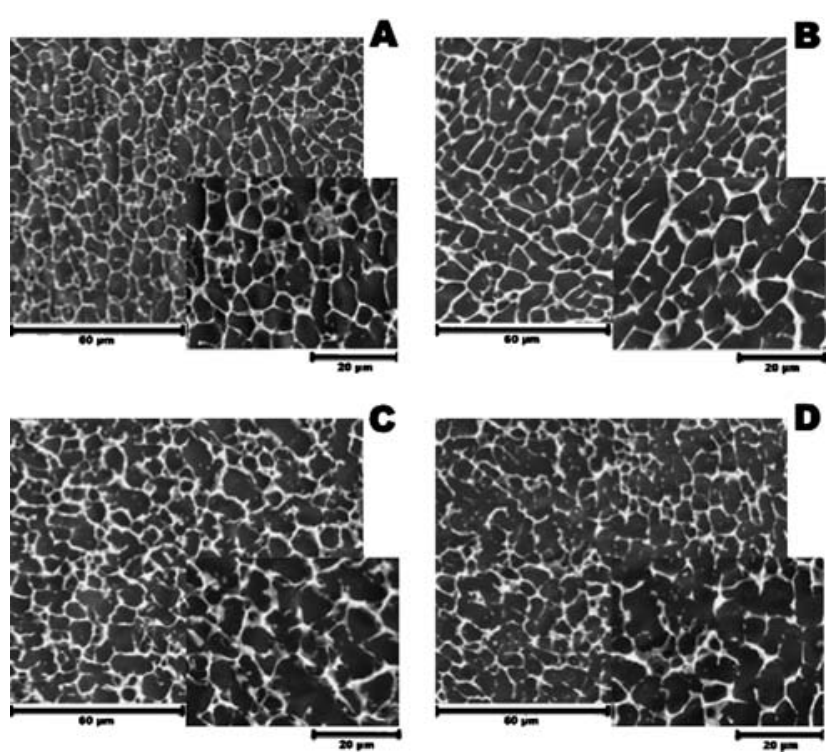

Fig. 4 CryoSEM images of the surface fracture of (A) CGP, (B) CS-I, (C) CS-II and (D) CS-III hydrogels in two different magnifications.

through the tissue. ${ }^{49}$ Therefore the characterization is of extreme importance for the solid-state rheological behaviour of the materials performed at physiological conditions to predict their mechanical performance in vivo. Generally the mechanical
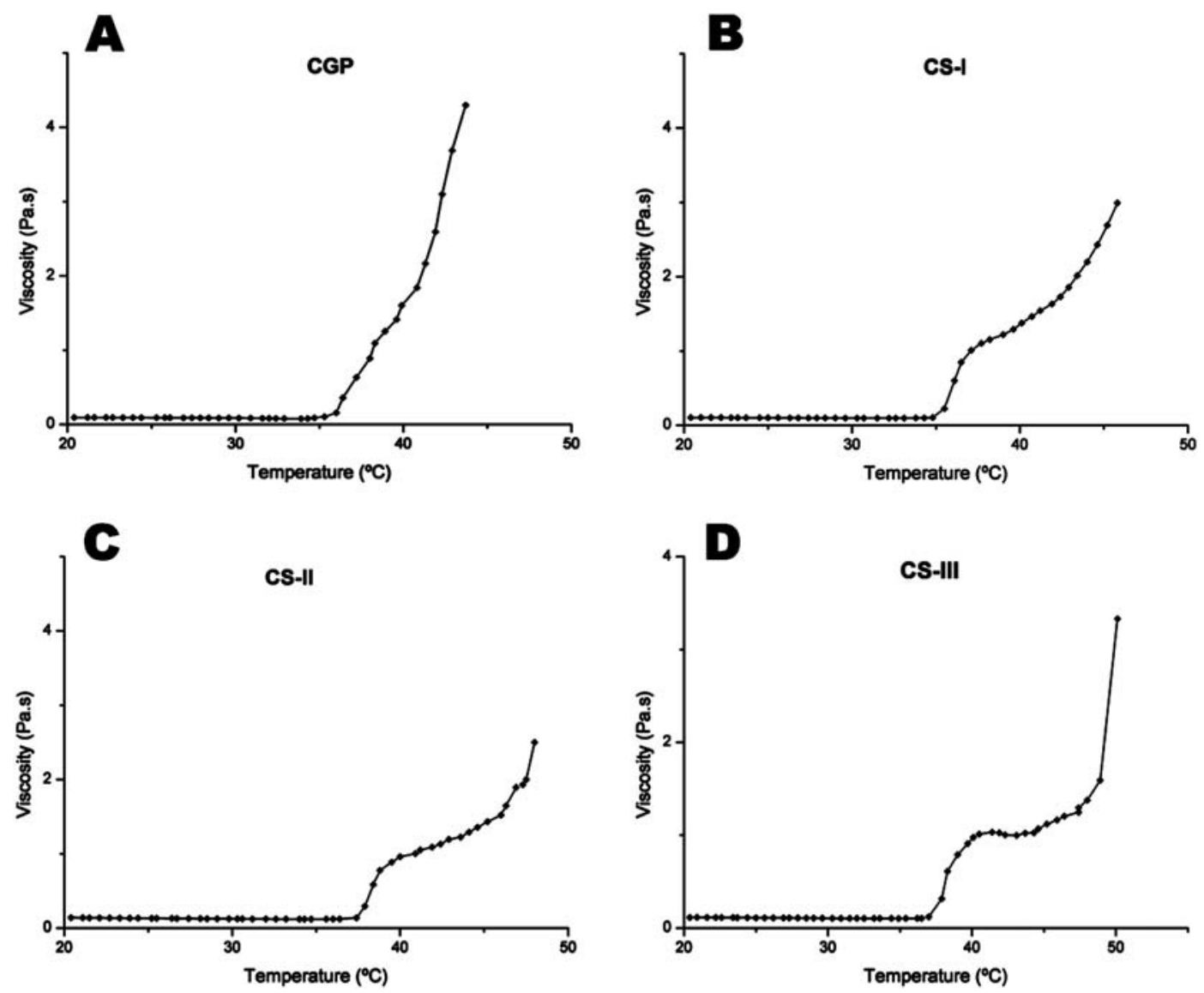

Fig. 3 Viscosity of: (A) CGP (B) CS-I, (C) CS-II and (D) CS-III solutions as function of temperature. 
properties in the hydrated state are acquired using samples previously wetted and measured in conventional equipment, but we believe that this is not enough and, therefore, in this work, the hydrogels were analysed with experimental data taken in physiological simulated solutions, i.e. the samples were totally immersed PBS, at body temperature, $-37{ }^{\circ} \mathrm{C}$, during the measurements.

Dynamic mechanical analysis, DMA, is a non-harmful technique in which the sample is subjected to an oscillatory stress and the follow-on strain is measured in function of a wide range of temperature and frequencies. DMA methods enable the accurate quantification of the viscoelastic properties of a variety of scaffolds for biomedical applications..$^{50-52}$

Fig. 5 shows the isothermal DMA response of CGP and CS-I, CS-II and CS-III hydrogels as a function of frequency in terms of storage modulus $\left(\mathrm{E}^{\prime}\right)$ and loss factor $(\tan \delta)$. The elastic component $\left(E^{\prime}\right)$ is related with the stiffness of the material, while $\mathrm{E}^{\prime \prime}$ (the viscous component) is associated with the dissipation of energy, as heat, due to internal friction at the molecular level. The loss factor, $\tan \delta$, is defined as the ratio $\mathrm{E}^{\prime \prime} / \mathrm{E}^{\prime}$.

It was observed, for all the compositions, that the storage modulus $\left(\mathrm{E}^{\prime}\right)$ tends to increase with increasing frequency (Fig. 5A). It was also observed that the elastic modulus increased significantly with the addition of higher concentrations of starch, indicating that the presence of starch improved the stiffness of the hydrogels materials $\left(5.5 \times 10^{4} \mathrm{~Pa}\right.$ for CGP and $2.0 \times 10^{5} \mathrm{~Pa}$ for CS-III). The higher stiffness was observed in the formulation with higher concentration of starch CS-III (Fig. 5A). Fig. 5B shows that $\tan \delta$ decreases within the CS formulations with increasing frequency with values typically higher than 0.2 , evidencing the clear viscoelastic nature of the structures.

Although these values are not optimal comparing the articular cartilage mechanical functions, ${ }^{53,54}$ they are in the same range of values found for other hydrogels proposed for cartilage tissue engineering approach. ${ }^{7,46}$ Furthermore, the cell encapsulation and ECM accumulation may result in a biomechanical improvement. Comparing with the chitosan basic system, these results clearly demonstrated that best viscoelastic properties were obtained with novel hydrogel starch-based formulations.

Three types of interactions are involved in the gelation process of CGP system: (1) electrostatic attraction between the phosphate group of GP and the ammonium groups of chitosan; (2) hydrogen bonding between polymer chains as a result of reduced electrostatic repulsion after neutralization of the chitosan solution with GP; and (3) chitosan-chitosan hydrophobic interactions. ${ }^{46}$

It was also demonstrated that the sol-gel transition occurs in two steps. Initially, the addition of a weak base, such as GP, will partially neutralize the polyelectrolyte chitosan and bring the solutions close to precipitation. Thereby, when heated, chitosan is induced to release its protons, which will be transferred to glycerol phosphate, thus allowing the attractive electrostatic interchain forces to promote chitosan precipitation and induce the sol-gel transition. ${ }^{55,56}$ As a result, a physically cross-linked hydrogel is formed.

The improved mechanical properties observed in the novel formulations containing starch may be explained by several possible interactions, although complementary studies will be necessary to establish the exact mechanisms involved. Starch is composed by amylose molecules which are essentially linear $\alpha(1 \rightarrow 4)$ glucan chains, and by amylopectin molecules which are highly branched and often contain small amounts of covalently bound phosphate. Potato starch is characterized by a high content of phosphate relative to other starch sources. ${ }^{57}$

FT-IR spectroscopy was used to confirm the presence of phosphate groups in the chemical structure of potato starch used to prepare the hydrogels. Several characteristic absorption bands of starch were identified in Fig. 6, such as $\mathrm{C}-\mathrm{O}, \mathrm{C}-\mathrm{H}$, and hydroxyl groups stretching vibration. Compared with native starch, the spectrum of potato starch showed a three new bands at 1168,1088 , and $918 \mathrm{~cm}^{-1}$, which were ascribed to $\mathrm{P}=\mathrm{O}$, $\mathrm{C}-\mathrm{O}-\mathrm{P}$, and $\mathrm{O}-\mathrm{P}-\mathrm{O}$ of the phosphate group, respectively. ${ }^{58}$ The appearance of these bands could be considered as an evidence for the occurrence of phosphate groups in starch.

The presence of these anionic groups may act as a proton sink, in a similar way observed on GP, and thus enhancing the electrostic attraction between the ammonium groups of chitosan and the phosphate groups of both GP and starch. The hydrophilic properties of starch might also contribute for the reinforcement in the mechanical properties of these CS formulations due to the ability to uptake water, raising up the rheological behavior of the starch-based hydrogels.
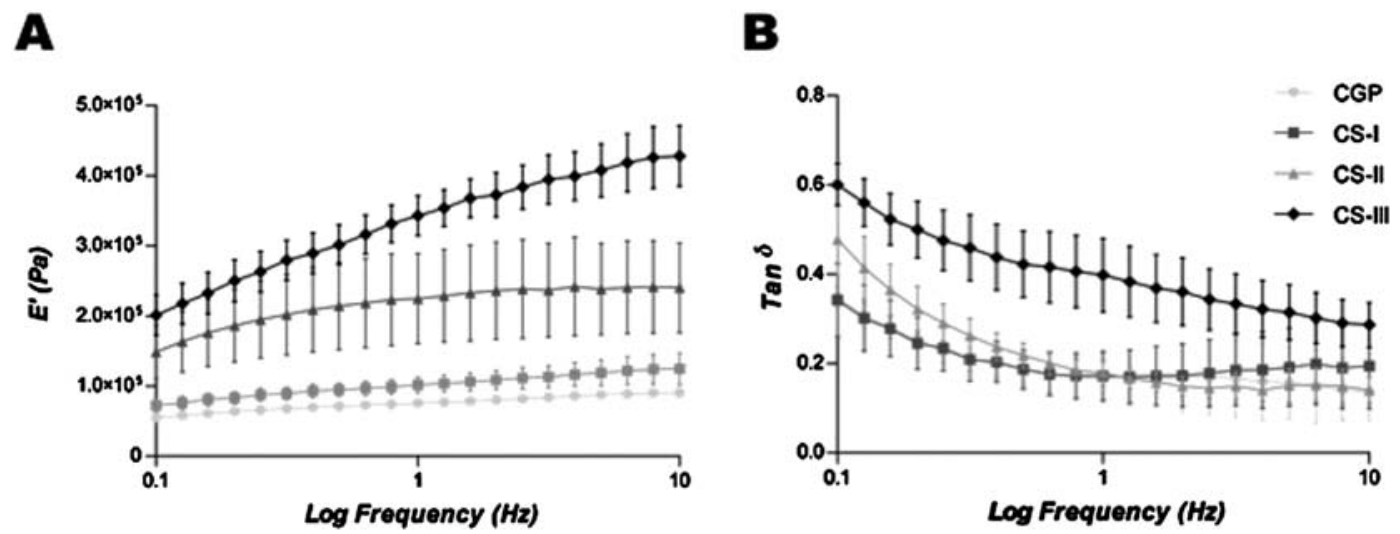

Fig. 5 Dynamic mechanical analysis of CGP and CS hydrogels as a function of frequency in terms of storage modulus, $\mathrm{E}^{\prime}$ (A), and loss factor, tan $\delta$ (B). 


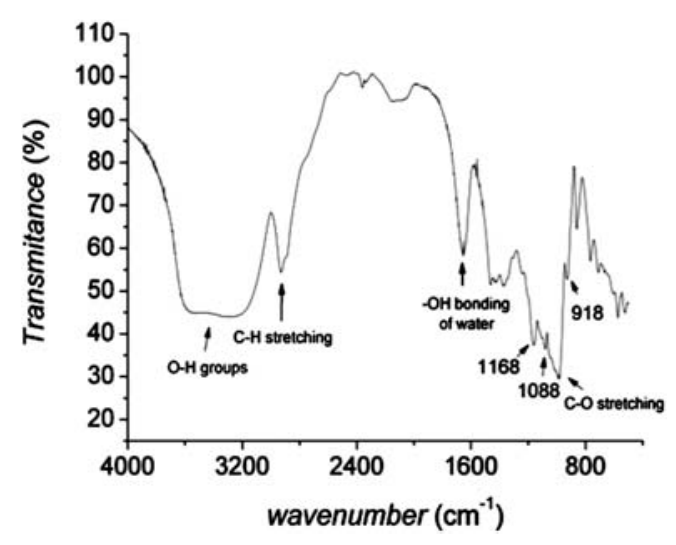

Fig. 6 FT-IR spectrum of potato starch containing phosphate groups.

\section{Degradation behaviour - in vitro enzymatic degradation study}

Biomaterial degradability is an important criterion for achieving optimal tissue regeneration with cell transplantation. The scaffolds should maintain its structural and mechanical integrity for long periods of time until the growing cartilage can support itself, hence they should degrade at a rate in line with the new tissue regeneration. A slow degradation profile can inhibit the tissue function, while a fast degradation can influence cell distribution and migration, as well as ECM deposition. ${ }^{3}$ There are a number of factors that influence the hydrogel degradation, such as hydrogel chemistry, crosslinkage, presence of cells and in vivo environment. ${ }^{9}$ Therefore, the in vitro degradation studies should be performed in simulated physiological environment.

In this work we propose a new set of hydrogel formulations based on two biodegradable materials: chitosan and starch. The degradation of chitosan in the human body is carried out primarily by lysozyme, an enzyme that destroys bacteria through cell wall disruption by catalysing hydrolysis of proteoglycans. ${ }^{59}$ In the human body, lysozyme is found in different body fluids and is part of the innate immune system, playing in this way, an important role following implantation of biomaterial. The in vivo degradation products of chitosan are non-toxic and non-immunogenic.

Starch is also known to be susceptible to enzymatic degradation. Many enzymes may be involved in starch degradation, among them $\alpha$-amylase, which is also found in human fluids. ${ }^{33}$

The main aim of studying the degradation behaviour using enzymes with similar concentration found in human serum is to simulate the physiological conditions. ${ }^{32}$ For that purpose, hydrogels were incubated with an enzyme cocktail containing $\alpha$-amylase $\left(150 \mathrm{U} \mathrm{L}^{-1}\right)$ and lysozyme $\left(13 \mathrm{mg} \mathrm{L}^{-1}\right)$ in PBS and their weight loss was followed over 60 days. In all the hydrogel conditions, it was possible to detect a gradual increase in weight loss (Fig. 7). An enhanced degradation rate was distinguished in all the starch-based formulation when compared with a CGP hydrogel, although no significant differences were observed in the degradation profile within the starch samples. It seems that the incorporation of starch in the formulations increased the degradation rate, but the selected concentrations were not high enough to observe between the CS-I, CS-II, and CS-III systems.

The combination of starch within chitosan-based hydrogel renders an improvement in the mechanical properties and

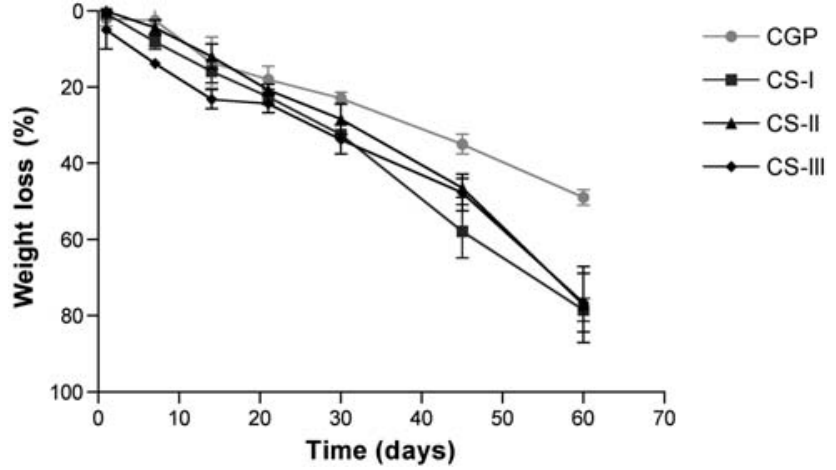

Fig. 7 Weight loss of CGP and CS hydrogels as function of time in PBS with $\alpha$-amylase $\left(150 \mathrm{U} \mathrm{L}^{-1}\right)$ and lysozyme $\left(13 \mathrm{mg} \mathrm{L}^{-1}\right)$.

degradation profile, suggesting the potential of these novel thermo-responsive hydrogels to be used as an injectable scaffolds for cartilage engineered applications.

\section{In vitro cytotoxicity screening on materials' extracts}

The biocompatibility of the developed systems is, as well, as issue of great importance. A cytotoxicity test was performed using the extracted leachables from hydrogels, where L929 cells were exposed to the degradation product release by those materials after immersion in culture medium and cultured up to 7 days. The viability MTS assay was performed and the cells show similar metabolic activities to those obtained by the negative control for cell death (tissue culture polystyrene - TCPS). The effects of the positive control (latex) were evident, conferring a strong decrease in cell viability as shown in Fig. 8. Therefore the leachables released from the hydrogels could be considered as noncytotoxic towards mouse fibroblasts cell line. This is in accordance with a previous study that had shown the biocompatibility of CGP hydrogels. ${ }^{60}$

In the present study, a novel chitosan-starch based set of hydrogels was proposed as vehicles for cell delivery in cartilage tissue regeneration. The data collected from rheological analysis confirmed that these new formulation exhibit an ability to be applied as a minimal invasive systems: the low initial viscosity of the solution allows the efficient distribution of the cell, together

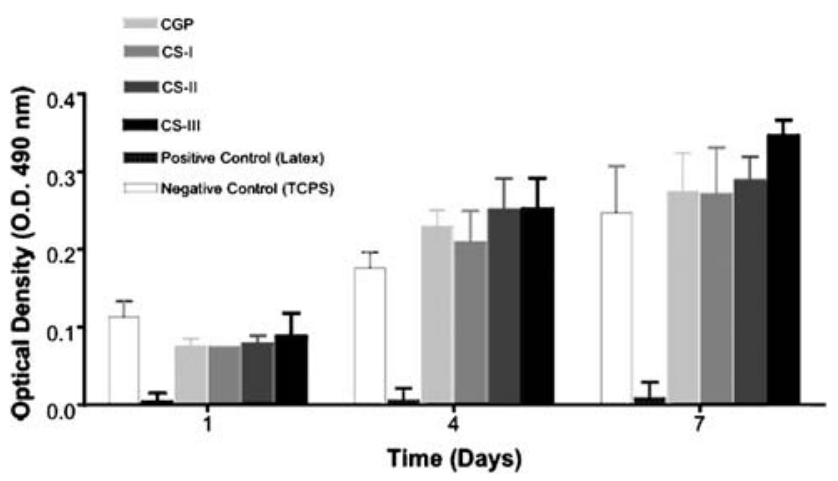

Fig. 8 Cytotoxicity screening for the CGP and CS hydrogels, positive control (latex rubber), and negative control (TCPS) extracts, incubated with L929 cells for 1, 4, and 7 days. 
with the formation of a stable hydrogel with entrapped cells when reached the body temperature. Improvements in the mechanical properties and degradation rates were also registered, corroborating the potential of these novel cell delivery systems for cartilage engineered treatments.

The succeeding cell encapsulation studies towards chondrogenesis were performed with the CS-II formulation, which will be named from now on as CST.

\section{Chondrogenesis of human adult adipose derived stromal cells ADSC encapsulated in CST hydrogel}

In a second phase of this study, we aim to evaluate the potential of chitosan- $\beta$-glycerophosphate (CGP) and chitosan- $\beta$-glycerophosphate- $1 \%$ starch (CST) hydrogels to induce chondrocytic differentiation and cartilage matrix accumulation of ADSCs. We also intend to explore whether the enhanced biomechanical properties of the starch formulation, above mentioned, might influence the chondrogenesis of the encapsulated ADSC cells.

During the last years, researches have been seeking novel chondrogenic cell sources, in a more abundant supply than chondrocytes, to promote articular tissue regeneration. The potential of stromal cells isolated from human adipose tissue (i.e., subcutaneous fat), to differentiate into a chondrocytic phenotype under defined culture conditions, either with or without cell laden scaffolds, has been evaluated in diverse studies. ${ }^{27,29,30}$

\section{Biochemical composition}

After isolation and expansion, 10 million cells were encapsulated in CGP and CST and cultured in chondrogenic medium. The biochemical composition of the constructs was determined to be dependent on time in culture (Fig. 9).

The total DNA content was evaluated using a fluorimetric dsDNA quantification kit (PicoGreen, Molecular Probes). The DNA gradually and significantly increased during the 4 weeks of culture in both hydrogel conditions, and reached values of $3.66 \mu \mathrm{g} \mathrm{DNA} /$ construct in the CGP and $5.78 \mu \mathrm{g} \mathrm{DNA} /$ construct in CST gel (Fig. 9A). These data indicated that ADSC after expansion, and once seeded within the thermoresponsive materials, maintain a proliferation potential and remain viable. Although the DNA values were similar in the firth 2 weeks of culture for both conditions, the DNA values were significantly higher in the starch-based constructs after 28 days of culture (Fig. 9A).

The sulfated glycosoaminoglycans (GAGs) are essential elements in native extracellular matrix. They have an important role in the tissue mechanical response, by enabling cartilage to bind water and account for the property of compressive stiffness that is crucial for the correct function of articular joints. ${ }^{61,62}$ GAGs were quantified using dimethylmethylene blue (DMB) assay. The assay is based on the ability of sulfated glycosaminoglycans to bind the cationic dye 1,9-dimethylmethylene blue. It is formed a glycosaminoglycan/dye complex, and the optical density measurement of the dissociated dye permitted quantification of glycosaminoglycans in biological samples.

The results of the assay revealed that the all the constructs exhibited an increase in proteoglycan accumulation (Fig. 9B). It is also noticeably evident that the GAGs level normalized to total DNA of ADSC/CST constructs were much higher that those of ADSC/CGP constructs. These results indicate that CST hydrogel allowed three-dimensional culture of ADSC able to synthesize a GAG-containing ECM, and gathers unequivocally an improved biochemical composition.

\section{Histological analysis}

Cell morphology and distribution within the constructs were examined by microscopy during the in vitro culture. H\&E histological staining revealed that the cells were uniformly distributed throughout the whole hydrogel and adopted a typical rounded morphology of native chondrocytes (Fig. 10A-B). This round-shaped morphology is one of the characteristics of the differentiated chondrocytic phenotype, ${ }^{63,64}$ which allows synthesis of cell-specific pericellular or intercellular matrix. The differentiated phenotype, together with the cell viability and distribution are important aspects to take into account when preparing tissue engineering implants.
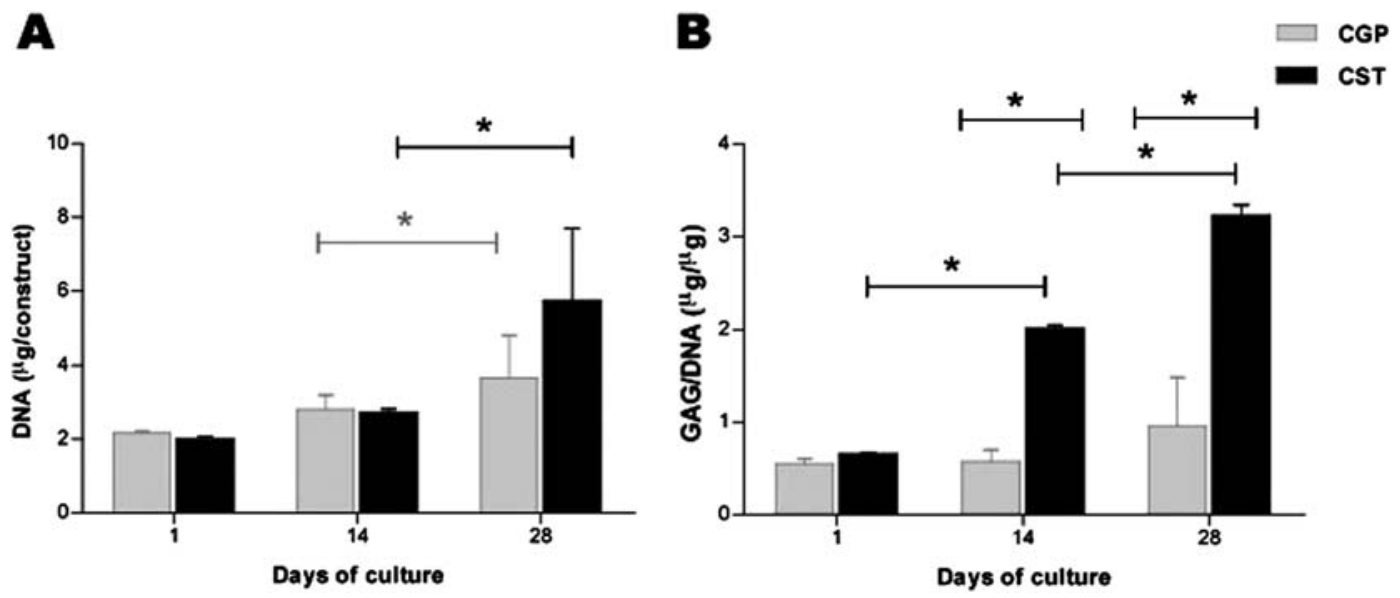

Fig. 9 ADSC cells proliferation when encapsulated in CGP and CST hydrogels (A), and sulfated glycosaminoglycan content normalized to the amount of DNA in the constructs. $(* \mathrm{p}<0.05$.) 

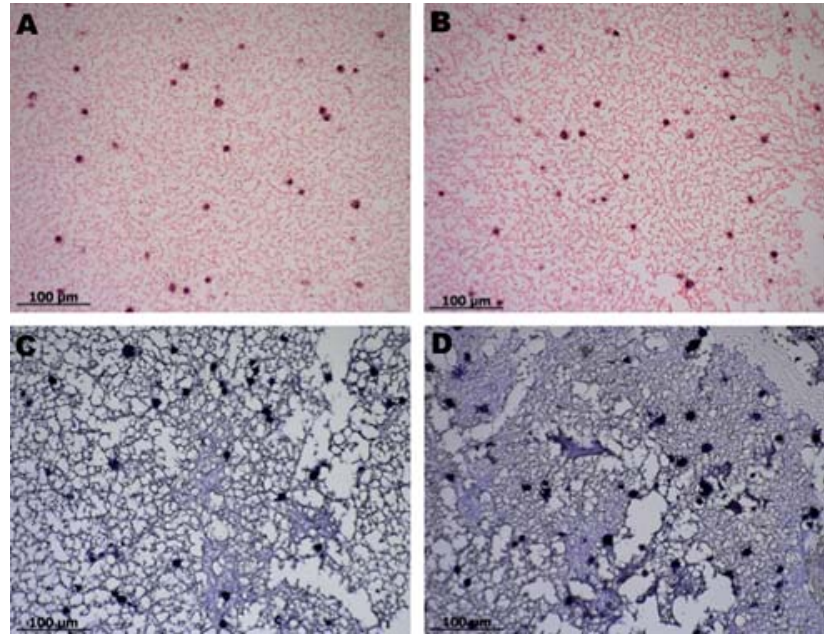

Fig. 10 H\&E histological sections of the CGP (A) and CST (B); and Toluidine Blue histological sections of the CGP (C) and CST (D) constructs taken after 28 days of culture.

Of utmost importance is also the accumulation of cartilagespecific macromolecules in the constructs to form an ECM similar to the native one. ${ }^{65}$ Sulfated glycosaminoglycans were detected in histological sections of the constructs after 4 weeks of culture using Toluidine Blue metachromatic staining
(Fig.10C-D). The positive staining was localized in the pericellular and extracellular regions throughout the hydrogels, although the metachromasia (indicative of cartilaginous matrix) was more evident in the starch constructs (Fig. 10D). The identification of proteoglycans in the ECM are in agreement with, and reinforce the previous results of the biochemical quantification of GAGs, being a positive indicator towards the formation of cartilage-like tissue.

\section{Real-time RT-PCR (collagen type II, type I, aggrecan, and Sox 9)}

The real-time RT-PCR analysis were performed after 1 and 4 weeks of culture to quantitatively assess the up- and downregulation of genes typically associated with chondrocytes and cartilage tissue formation. The analysis of Sox 9, collagen I, collagen II, and aggrecan genes were performed, normalized to GAPDH housekeeping expression and the comparative $2^{-\Delta \Delta \mathrm{Ct}}$ (Livak) method was used to analyse the results.

Collagen type II, IX, X and XI are traditionally considered specific for cartilage, and they are present at different stages of chondrogenic process. Collagen type II is involved in weight bearing and adsorbing functions and is the major protein produced by chondrocytes in articular cartilage. ${ }^{48,63}$ Aggrecan is also one of the most important components of ECM, being the main proteoglycan, and its primary function is to give viscoelastic compressive properties to the cartilage. The expression of
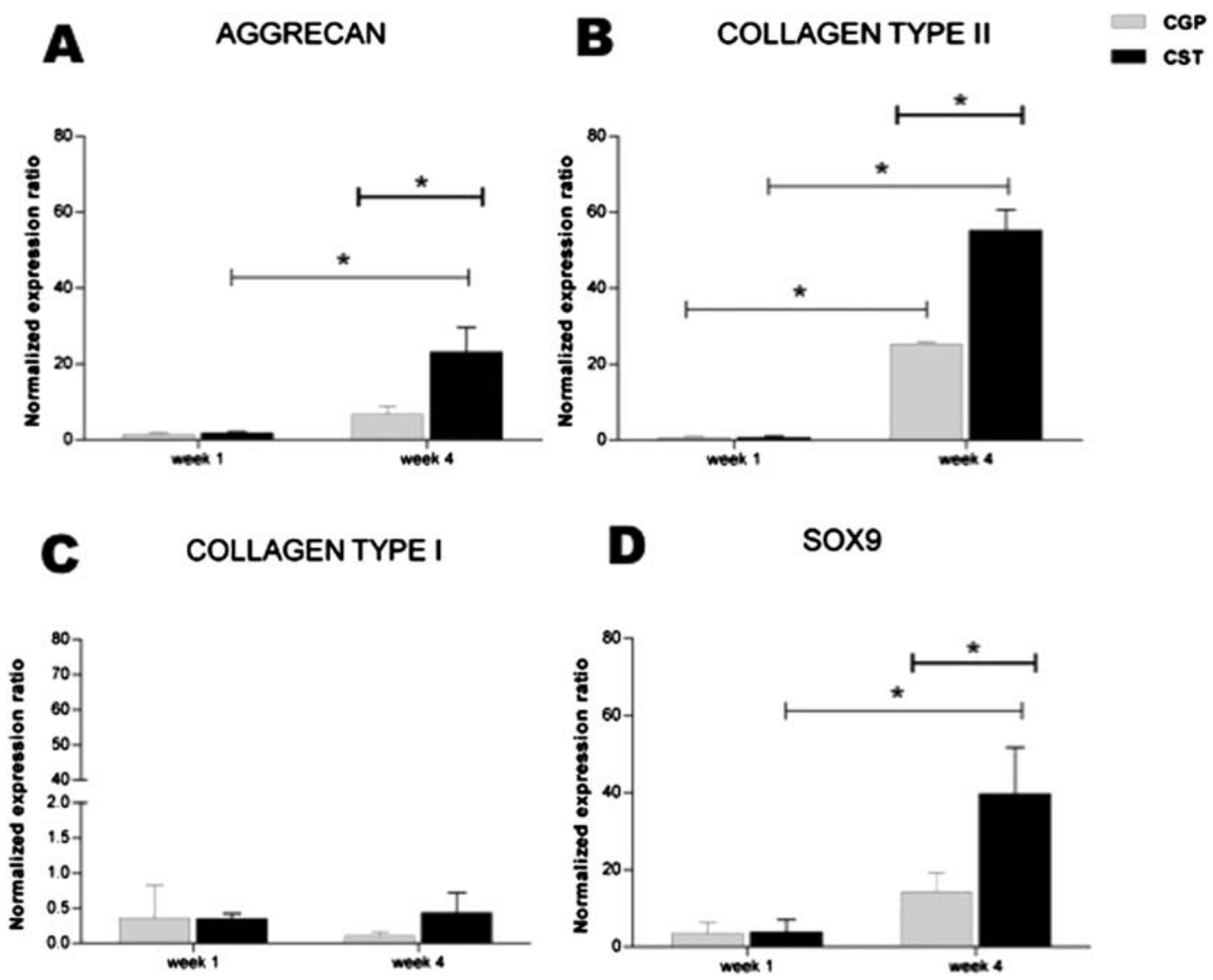

Fig. 11 Graphical representation of the realtime semiquantitative PCR analysis for aggrecan (A), collagen type II (B), collagen type I (C), Sox 9 (D) based on the mRNA produced by the encapsulated ADSC after 1 and 4 weeks of culture $(* p<0.05)$. 
Sox 9 is the first step towards chondrogenesis and is responsible for the expression of some key genes, thus regulating some important events throughout chondrogenesis. Hence, the detection of Sox 9, collagen type II, and aggrecan are positive indicators of the hyaline-like nature of tissue engineered constructs.

Collagen type I is associated with the dedifferentiation process and it is a characteristic feature of chondrocytes grown in twodimensional cultures. It is well known that during monolayer expansion, the chondrocytes adopt a more fibroblast-like morphology, accompanied by the up-regulation of type I collagen expression, and thus its presence is a poor indicator of an articular ECM-like matrix. ${ }^{48}$

The graphical representation of the molecular expression (Fig. 11) shows that collagen type I levels were residual after one and four weeks of culture either in CGP and CST hydrogels. In both conditions there was a significant increase in collagen type II, Sox 9 and aggrecan. The upregulation profile of these genes was higher on the CST constructs when compared with CGP at week 4. The increase in collagen type II in CST was more than 30 fold greater than in CGP hydrogels; and $\sim 17$ fold greater in both aggrecan and Sox 9, after 28 days of culture. The realtime RT-PCR suggested that ADSC were undergoing chondrogenic differentiation, by the expression and deposition of ECM components.

These analyses strengthened the ability of these thermoresponsive hydrogels to induce and support the chondrocytic differentiation of adipose derived stromal cells in vitro, with a significant enhancement in the novel CST construct towards a development of an hyaline like tissue.

\section{Conclusions}

Novel formulations based on chitosan- $\beta$-glycerophosphate and the combination of starch, were proposed as thermoresponsive injectable systems for cell delivery and support, aiming cartilage regeneration through engineered strategies.

The rheological measurements showed that the addition of starch to the chitosan-GP solution did not alter the transition temperature and confirmed the heating inducing gelation of all solutions, which remain liquid at room temperature and solidifies into white hydrogels near body temperature, supporting the ability of these formulations to be applied as a minimal invasive systems. The evaluation of the dynamic mechanical analysis of the hydrogels showed an increase in the storage modulus within increasing starch concentration, clearly demonstrating that better mechanical behavior could be obtained with novel hydrogel formulations. The incorporation of starch also improved the degradation profile. All the conditions showed to be biocompatible through the citotoxicity screening in vitro. Added together these data suggested the potential of these novel thermo-responsive chitosan- $\beta$-glycerophosphate hydrogels to be used as an injectable scaffolds for cartilage engineered applications.

In a second phase of this study, we demonstrated the suitability of chitosan- $\beta$-glycerophosphate (CGP) and chitosan- $\beta$ glycerophosphate- $1 \%$ starch (CST) hydrogels to promote differentiation of ADSCs and maintained the chondrogenic phenotype. The cells were homogeneously encapsulated, remain viable, proliferated, and maintained the expression of typical chondrogenic markers genes, and deposited cartilage ECM molecules. These results were remarkably improved within the novel CST constructs. The in vitro performance of the CST hydrogels generated interesting and promising results that justify further in vivo studies to give a definitive evaluation towards a development of a hyaline like tissue.

The overall data shows that chitosan- $\beta$-glycerophosphatestarch hydrogels in combination with adipose derived stromal cells constitute a promising approach for cartilage regeneration using a minimal invasive technique.

\section{Acknowledgements}

The authors acknowledge the financial support to the Portuguese Foundation for Science and Technology (FCT) for the PhD fellowship to H. Sá-Lima (SFRH/BD/21779/2005) and for the Project PTDC/QUI/68804/2006; the European Union funded STREP Project HIPPOCRATES (NM3-CT-2003-505758); and the European NoE EXPERTISSUES (NMP3-CT-2004-500283).

The authors would also like to thank the patients at Hospital da Prelada, Porto, Portugal for the donation of the biological samples, and the medical staff, in particular Dr Paulo Costa, for their help and support. Finally the authors would also like to thank J. V. Araújo for the initial help with the hydrogels preparation.

\section{References}

1 C. Vinatier, D. Mrugala, C. Jorgensen, J. Guicheux and D. Noel, Trends Biotechnol., 2009, 27, 307-314.

2 H. Chiang and C. C. Jiang, J. Formosan Med. Assoc., 2009, 108, 87101.

3 A. Getgood, R. Brooks, L. Fortier and N. Rushton, J. Bone Jt. Surg., Br. Vol., 2009, 91-b, 565-576.

4 E. S. Place, N. D. Evans and M. M. Stevens, Nat. Mater., 2009, 8, 457-470.

5 J. Raghunath, J. Rollo, K. M. Sales, P. E. Butler and A. M. Seifalian, Biotechnol. Appl. Biochem., 2007, 46, 73-84.

6 R. Stoop, Injury, 2008, 39(1), 77-87.

7 J. T. Oliveira, L. Martins, R. Picciochi, P. B. Malafaya, R. A. Sousa, N. M. Neves, J. F. Mano and R. L. Reis, J Biomed Mater Res A, 2009.

8 R. C. Pereira, M. Scaranari, P. Castagnola, M. Grandizio, H. S. Azevedo, R. L. Reis, R. Cancedda and C. Gentili, J. Tissue Eng. Regener. Med., 2009, 3, 97-106.

9 B. V. Slaughter, S. S. Khurshid, O. Z. Fisher, A. Khademhosseini and N. A. Peppas, Adv. Mater., 2009, 21, 3307-3329.

10 J. F. Mano, Adv. Eng. Mater., 2008, 10, 515-527.

11 G. D. Nicodemus and S. J. Bryant, Tissue Eng., Part B: Rev., 2008, 14, 149-165.

12 L. Yu and J. Ding, Chem. Soc. Rev., 2008, 37, 1473-1481.

13 I. Y. Kim, S. J. Seo, H. S. Moon, M. K. Yoo, I. Y. Park, B. C. Kim and C. S. Cho, Biotechnol. Adv., 2008, 26, 1-21.

14 A. Di Martino, M. Sittinger and M. V. Risbud, Biomaterials, 2005, 26, 5983-5990.

15 A. Chenite, C. Chaput, D. Wang, C. Combes, M. D. Buschmann, C. D. Hoemann, J. C. Leroux, B. L. Atkinson, F. Binette and A. Selmani, Biomaterials, 2000, 21, 2155-2161.

16 J. Berger, M. Reist, A. Chenite, O. Felt-Baeyens, J. M. Mayer and R. Gurny, Int. J. Pharm., 2005, 288, 197-206.

17 M. H. Cho, K. S. Kim, H. H. Ahn, M. S. Kim, S. H. Kim, G. Khang, B. Lee and H. B. Lee, Tissue Eng. A, 2008, 14, 1099-1108.

18 C. D. Hoemann, A. Chenite, J. Sun, M. Hurtig, A. Serreqi, Z. Lu, E. Rossomacha and M. D. Buschmann, J. Biomed. Mater. Res., Part A, 2007, 83a, 521-529.

19 D. S. Couto, Z. Hong and J. F. Mano, Acta Biomater., 2009, 5, 115123. 
20 J. S. Barbosa, A. Ribeiro, A. M. Testera, M. Alonso, F. J. Arias, J. C. Rodrİguez-Cabello and J. o. F. Mano, Adv. Eng. Mater., 2010, 12, B37-B44.

21 J. T. Oliveira, A. Crawford, J. M. Mundy, A. R. Moreira, M. E. Gomes, P. V. Hatton and R. L. Reis, J. Mater. Sci.: Mater. Med., 2007, 18, 295-302.

22 P. B. Malafaya, G. A. Silva and R. L. Reis, Adv. Drug Delivery Rev., 2007, 59, 207-233.

23 R. L. Reis and A. M. Cunha, in Encyclopedia of Materials: Science and Technology, ed. K. H. J. r. Buschow, W. C. Robert, C. F. Merton, I. Bernard, J. K. Edward, M. Subhash and V. Patrick, Elsevier, Oxford, 2001, pp. 8810-8815.

24 J. F. Mano, G. A. Silva, H. S. Azevedo, P. B. Malafaya, R. A. Sousa, S. S. Silva, L. F. Boesel, J. M. Oliveira, T. C. Santos, A. P. Marques, N. M. Neves and R. L. Reis, J. R. Soc. Interface, 2007, 4, 999-1030.

25 A. Barbero, S. Grogan, D. Schafer, M. Heberer, P. Mainil-Varlet and I. Martin, Osteoarthritis Cartilage, 2004, 12, 476-484.

26 A. Barbero, S. Ploegert, M. Heberer and I. Martin, Arthritis Rheum., 2003, 48, 1315-1325.

27 T. Rada, R. L. Reis and M. E. Gomes, Tissue Eng., Part B: Rev., 2009, 15, 113-125.

28 M. K. El Tamer and R. L. Reis, J. Tissue Eng. Regener. Med., 2009, 3, 327-337.

29 H. Tapp, E. N. Hanley, J. C. Patt and H. E. Gruber, Exp Biol Med (Maywood), 2008.

30 J. M. Gimble, A. J. Katz and B. A. Bunnell, Circ. Res., 2007, 100, $1249-1260$.

31 H. Mizuno, J. Nippon Med. Sch., 2009, 76, 56-66.

32 J. Hankiewicz and E. Swierczek, Clin. Chim. Acta, 1974, 57, 205-209.

33 H. S. Azevedo, F. M. Gama and R. L. Reis, Biomacromolecules, 2003, 4, 1703-1712.

34 S. G. Dubois, E. Z. Floyd, S. Zvonic, G. Kilroy, X. Wu, S. Carling, Y. D. Halvorsen, E. Ravussin and J. M. Gimble, Methods Mol. Biol., 2008, 449, 69-79.

35 W. Kafienah and T. J. Sims, Methods Mol Biol, 2004, 238, 217-229.

36 K. J. Livak and T. D. Schmittgen, Methods, 2001, 25, 402-408.

37 D. Hannouche, Rev Chir Orthop Reparatrice Appar Mot, 2008, 94, 383-393.

38 E. Ruel-Gariépy and J. C. Leroux, Eur. J. Pharm. Biopharm., 2004, 58, 409-426.

39 C. D. Hoemann, J. Sun, A. Legare, M. D. McKee and M. D. Buschmann, Osteoarthritis Cartilage, 2005, 13, 318-329.

40 M. S. Shive, C. D. Hoemann, A. Restrepo, M. B. Hurtig, N. Duval, P. Ranger, W. Stanish and M. D. Buschmann, Oper. Tech. Orthop., 2006, 16, 271-278.

41 M. Gomes, H. Azevedo, P. Malafaya, S. Silva, J. Oliveira, G. Silva, R. Sousa, J. Mano, R. Reis, B. Clemens van, T. Peter, L. Anders,
H. Jeffrey, F. W. David, C. Ranieri, D. d. B. Joost and S. Jérôme, in Tissue Engineering, Academic Press, Burlington, 2008, pp. 145192.

42 N. M. Alves, C. Saiz-Arroyo, M. A. Rodriguez-Perez, R. L. Reis and J. F. Mano, Acta Biomater., 2007, 3, 69-76.

43 E. T. Baran, J. F. Mano and R. L. Reis, J. Mater. Sci.: Mater. Med., 2004, 15, 759-765.

44 J. Cho, M. C. Heuzey, A. Begin and P. J. Carreau, Biomacromolecules, 2005, 6, 3267-3275.

45 A. Chenite, M. Buschmann, D. Wang, C. Chaput and N. Kandani, Carbohydr. Polym., 2001, 46, 39-47.

46 E. Ruel-Gariépy, A. Chenite, C. Chaput, S. Guirguis and J. C. Leroux, Int. J. Pharm., 2000, 203, 89-98.

47 L. A. McMahon, F. J. O'Brien and P. J. Prendergast, Regener. Med., 2008, 3, 743-759.

48 T. Trzeciak and M. Richter, Chir Narzadow Ruchu Ortop Pol, 2008, 73, $107-111$.

49 V. C. Mow, M. H. Holmes and W. M. Lai, J. Biomech., 1984, 17, $377-$ 394.

50 D. S. Jones, Int. J. Pharm., 1999, 179, 167-178.

51 S. Ghosh, V. Gutierrez, C. Fernandez, M. A. Rodriguez-Perez, J. 1. C. Viana, R. L. Reis and J. o. F. Mano, Acta Biomater., 2008, 4, 950-959.

52 D. M. García Cruz, D. F. Coutinho, J. F. Mano, J. L. Gómez Ribelles and M. Salmerón Sánchez, Polymer, 2009, 50, 2058-2064.

53 C. J. Schwartz and S. Bahadur, Wear, 2007, 262, 1315-1320.

54 G. R. Fulcher, D. W. Hukins and D. E. Shepherd, $B M C$ Musculoskeletal Disord., 2009, 10, 61.

55 D. Filion, M. Lavertu and M. D. Buschmann, Biomacromolecules, 2007, 8, 3224-3234.

56 M. Lavertu, D. Filion and M. D. Buschmann, Biomacromolecules, 2008, 9, 640-650.

57 T. Posternak, J Biol Chem, 1951, 188, 317-325.

58 W. Xie and L. Shao, Starch - Stärke, 2009, 61, 702-708.

59 R. J. Nordtveit, K. M. Varum and O. Smidsrod, Carbohydr. Polym., 1996, 29, 163-167.

60 R. Ahmadi and J. D. De Bruijn, J. Biomed. Mater. Res., Part A, 2008, 86a, 824-832.

61 J. Musilova, J. Musil and A. Susta, Acta Univ Carol Med (Praha), 1976, 22, 19-25.

62 M. T. Bayliss and S. Y. Ali, Biochem J, 1978, 176, 683-693.

63 R. Cancedda, F. Descalzi Cancedda and P. Castagnola, Int. Rev. Cytol., 1995, 159, 265-358.

64 Z. Lin, C. Willers, J. Xu and M.-H. Zheng, Tissue Eng., 2006, 12, 1971-1984.

65 C. Gentili and R. Cancedda, Curr. Pharm. Des., 2009, 15, 1334 1348 . 